This item was submitted to Loughborough's Research Repository by the author.

Items in Figshare are protected by copyright, with all rights reserved, unless otherwise indicated.

\title{
Investigation into the role of core industrial designers in ecodesign projects
}

PLEASE CITE THE PUBLISHED VERSION

PUBLISHER

(C) Elsevier

LICENCE

CC BY-NC-ND 4.0

\section{REPOSITORY RECORD}

Lofthouse, V.A.. 2019. "Investigation into the Role of Core Industrial Designers in Ecodesign Projects". figshare. https://hdl.handle.net/2134/1007. 
This item was submitted to Loughborough's Institutional Repository by the author and is made available under the following Creative Commons Licence conditions.

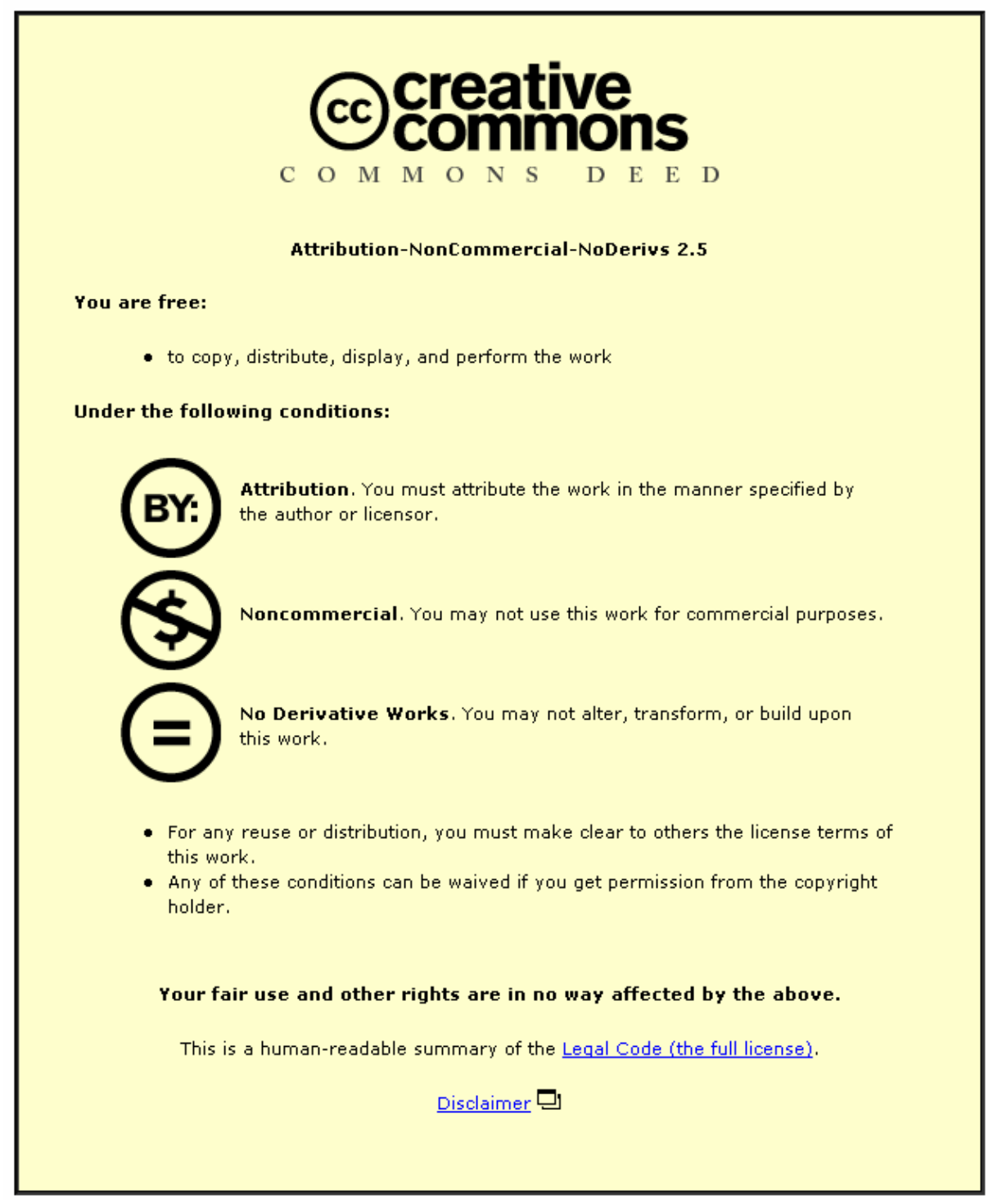

For the full text of this licence, please go to: http://creativecommons.org/licenses/by-nc-nd/2.5/ 
Investigation into the Role of Core Industrial Designers in Ecodesign Projects

Dr. Vicky Lofthouse,

Department of Design and Technology,

Loughborough University,

Loughborough,

Leics.

LE11 3TU

\section{Abstract}

Current ecodesign theory supports the belief that industrial designers have a valuable role to play in ecodesign because of their position at the early stages of the product development process ${ }^{1}$. Despite this, current literature provides little evidence as to what this role should entail and whether this role is limited to industrial designers working at the strategic end of ecodesign. This paper provides empirical evidence to support the theory that there is a specific and valuable role for core industrial designers working at the operational end of ecodesign and presents the first detailed understanding of what this role involves.

\section{Keywords}

eco design; industrial design; product design 
Current ecodesign theory supports the belief that industrial designers have a valuable role to play in ecodesign because of their positioning at the early stages of the product development process (PDP) where the design brief is most flexible and the most critical decisions with respect to; cost, appearance, materials selection, innovation, performance, environmental impact, and perceptions of quality (longevity, durability, reparability), are made $^{1,2}$. Despite this, until recently there has been minimal discussion regarding exactly what role industrial designers play in ecodesign. This paper draws on the findings that emerged from a 3 year collaborative research project between Cranfield University and AB Electrolux which started in 1998 and set out to provide an insight into the role that core industrial designers play in ecodesign projects.

\section{Background to the project}

The project presented, was initiated part way through another Cranfield-Electrolux collaboration which started in 1997. This work is reported on in Sherwin's doctoral thesis “Innovative Ecodesign - An Exploratory and Descriptive Study of Industrial Design Practice" ${ }^{3}$. Sherwin's involvement with Electrolux was concerned primarily with the conceptual end of ecodesign and led to a more detailed understanding of the role that concept designers can play in ecodesign. The success of the original collaboration encouraged Electrolux Industrial Design to look beyond conceptual ecodesign projects, towards integrating ecodesign into the design and development of core products. Within this paper 'core design' is understood to be design which focuses on the development of a new product platform (in contrast to concept design which focuses on the generation of new concepts). It was this motivation, in conjunction with the President of Industrial Design's desire to “...be photographed next to the best-in-class environmental cooker in the world!” that led to the initiation of the second collaborative project. 
However, during the very early stages of this project it was quickly recognised that despite their enthusiasm, the industrial designers did not know how to go about developing ecodesign concepts into realised products. What was missing was an understanding of the role that core design should play in ecodesign and of the types of support mechanisms that were needed to sustain this role. The project reported in this paper set out to identify a much stronger understanding of the role that core industrial designers can play in ecodesign and develop a more detailed understanding of how to support these designers when they are involved in ecodesign focused projects. This was considered important, not only with regards to educating the Electrolux designers and giving them a sense of 'role', but also in terms of ensuring that any new tools or resources fit with the requirements of the industrial designers being asked to use them.

\section{Methodology}

Within this doctoral study, a prototype web based tool ('Information/Inspiration') was developed from the empirical findings collected during the pilot study ${ }^{4}$, in order to facilitate data collection. A deliberate decision was taken to make 'Information/Inspiration' a working prototype, primarily developed as a mechanism for collecting data rather than a finished product. It was felt that using a non-perfect prototype of an 'in-progress' nature would encourage discussion and enhance the development process.

"A prototype is something that you can touch, put in your pocket, play with in your hands. You can literally weigh it up. Prototypes are a fantastic way of evoking new insights and builds, and of checking what works and what doesn't. As soon as one prototype is finished and has been interrogated, a new one can be started... the real value comes from looping the loop (p.111)... Prototypes are rough and ready. That's part of their charm. They are the best you can do with the time and available 
resources. If a prototype is too finished, it actually stops people from commenting. If it’s that finished, they think, then it’s not longer under development.” (p.118) ${ }^{5}$

Mock-ups of this nature are regularly used in design practice, and as such are something which industrial designers are familiar with. It was anticipated that using this type of mechanism to collect data would provide the designers with enough substance to enable them to comment on the appropriateness of the approaches and content presented, whilst provoking them to identify the information requirements which were missing and comment on any inappropriate approaches used. The aim being to encourage a combination of positive and negative feedback that could provide a rich insight into the designers' needs and enhance the future development of the tool.

The prototype tool was used in conjunction with a wide range of data collection techniques, including semi-structured interviews, active and passive observation, and 'web-based feedback' to collect rich qualitative data from the industrial designers involved in the study. The resultant data was analysed using a coding and clustering approach, common in qualitative research ${ }^{6-8}$. The emergent findings were used to build up a rich picture of the role that core industrial designers wish to play in ecodesign projects and types of information that they need to support this role. Comments such as "I wish it had..." and "I like the fact that it shows..." were common during the interviews and helped to provide evidence for the type of activities that the participants wanted to be involved in. The findings which emerged regarding the role that core industrial designers can play in ecodesign, are presented in this paper.

\section{Understanding the relationship between the design elements of the PDP}

Within the context of this paper it is important to understand the relationships between concept industrial designers, core industrial designers and design engineers and the 
different roles that they play in the PDP. This section will explain the relationship between the three functions, by referring to the diagram in Figure 1 and outline the main activities that they are involved in.

Figure 1 shows that both concept industrial designers and concept design engineers feed into the conceptual design phase of the PDP. The main purpose of this phase is to generate new ideas and new concepts of both a technical and non-technical nature. The industrial designers focus on developing new product concepts to challenge and complement strategic business $3,9,10$. The design engineers focus on developing new technological innovations that can be integrated into product development at a later date (e.g. they might focus on developing new suction technologies for future product iterations) ${ }^{11}$. Design concepts generated at this stage may or may not be based in reality. During the conceptual design stage the design process is rapid and interactive. Once industrial designers have been given a brief for a project, they 'pick it up and run with it'. More often than not, their first hunches for solutions are drawn from their stored tacit knowledge, gained from previous design projects and from design education. They use mood boards to stimulate and contextualize design, and to create a 'sense' of the product. Ideas are generated through the use of individual and group brainstorming sessions. This stage will typically involve, “the production of sketches, drawings, mock-ups, 'lash-ups’ or models to test basic technical feasibility, assess proposed production methods, etc.” 12 . This stage results in the production of one or more design concepts which are fed into the next stages of the PDP. It is worth noting that core designers may also have some input into the conceptual design phase if this is appropriate for the product under development. 
The next phase in the design process is the embodiment stage, during which time the design is developed and scope is added to the initial concepts. This is where the main role of core design is to be found. During this stage designers will investigate competitors products by taking them apart to see how they work and how they are manufactured. Concepts will be embodied through the use of 2D sketches, 3D card models, CAD models, layout drawings, schematics and mock-ups. Mock-ups and/or prototypes will be used to test technical principles such as users' needs, component configuration and manufacturing capabilities, visualise layouts and ensure that styling encourages a certain use ${ }^{13}$. Performance calculations and decisions on materials and finishes will also be made at this stage.

At some point during the detail design phase core Industrial Design will hand over the project to Design Engineering, depending on the nature and complexity of the project. Within this stage industrial designers and design engineers use manufacturing and material knowledge to ensure that designs are efficient and profitable to produce ${ }^{9,10}$, and issues such as safety and usability are refined. By the end of the stage, the working drawings that provide information on the materials selected, tolerances and manufacturing processes, are passed onto the production elements of the PDP. Finally, the product enters the manufacture phase of the PDP, where design engineers liaise with the production team.

Although Figure 1 clearly demonstrates the differences between concept and core Industrial Design, and provides an understanding of the relationship between core Industrial Design and Design Engineering it is helpful to draw from the design literature to further clarify the differences between the roles of the latter two functions. Tovey ${ }^{9}$ and 
Svengren ${ }^{10}$ both agree that it is the industrial designers' concern with a product's expressive qualities - what it says about itself and its owner, that differentiates between Industrial Design and Design Engineering, a difference of emphasis that has emerged from Industrial Design's Arts and Craft based roots. Differences in the focus of the two functions have also been recognised, for example the focus of Industrial Design is often described as being 'people-centred' or 'user-centred' whereas the focus of Design Engineering is described as 'technology-centred' ${ }^{14,15}$. Where industrial designers aim to explain the function, encourage a certain use and express identity through a product, design engineers use, “...scientific principles, technical information and imagination in the definition of the mechanical structure, machine or system to perform pre-specified functions with maximum economy and efficiency” ${ }^{16}$. In addition to this, as illustrated in Figure 2, the 'typical' industrial designer has proficiencies across a wide range of skill sets such as artistry, mechanical design, marketing and psychology, whereas the 'typical' design engineer is expert in areas of mechanical design, materials/ manufacturing and electronic design ${ }^{17}$.

A number of authors also agree that there are differences between the way in which the two functions think ${ }^{18-21}$. Lawson ${ }^{18}$ cited in Cooper and Press ${ }^{19}$ explains that "thinking is usually categorised in two ways. On the one hand is reasoning, rational or convergent thinking, and on the other is imaginative, intuitive or divergent thinking. The former is logical, purposeful and concerned with outward directed problem solving, while the latter is unstructured, at times aimless and more inwardly directed.” Although industrial designers use both these modes of thinking, and controlling and combining these is considered to be one of the most important skills of a designer $\left({ }^{18}\right.$ cited in $\left.{ }^{19}\right)$, these different ways of thinking provide a useful way of differentiating between Industrial 
Design and Design Engineering. Joyce et al. ${ }^{20}$ and Durling et al. ${ }^{21}$ agree that designers are predominantly divergent thinkers, thinking which "is characterised by ideation and a fluency with unusually associated ideas... Any one of the ideas generated may be acceptable” ${ }^{21}$. In contrast to this, engineers are convergent thinkers, so aim to progress "toward the production of a single, right answer to a problem... characterised by a logical, analytical approach to problem-solving” ${ }^{21}$. So although both disciplines deal in problem solving through 'design', they each approach it in very different ways.

The final difference between the two functions relates to their learning styles. Durling ${ }^{22}$ refers to Schmeck's ${ }^{23}$ definition of learning styles, as being, "relatively stable ways in which individuals prefer to receive and assimilate new information in a learning context.” Durling continues by stating that, "...the style of teaching in design matches closely the learning preferences of art-based design students, and that designers' learning preferences differ significantly from some other professionals such as engineers and business managers" $^{22}$.

All the evidence in this section suggests some quite radical differences between the different design functions which contribute to the product development process.

\section{Current understanding of the role of industrial designers in ecodesign}

In 1995 Bakker ${ }^{2}$ identified two different roles for industrial designers in ecodesign, operational and strategic. She defines the operational role as being where industrial designers "translate product ideas into concrete ideas" and the strategic role as being where "designers tend to become more and more involved in the strategic phases of the product development process” ${ }^{2}$. Her findings suggest that concept designers would be 
more likely to focus on strategic ecodesign and that core industrial designers would be more likely to focus on the operational end of ecodesign.

However, Sherwin ${ }^{3}$ suggests there is little or no role for core industrial designers within ecodesign, that the role of industrial designers in ecodesign is limited to the conceptual stages (strategic ecodesign) and that the 'operational' issues are then picked up again by design engineering. The findings from his empirical study with the Electrolux designers suggest little recognition of any 'operational' role for industrial designers in ecodesign,

"There was also a strong sense that such types of ecodesign activities (more generally conducted at the detail design stages) are little influenced by Industrial Design, as they do not consider or undertake such design details and rarely, if ever for example specify materials.” (p.168) ${ }^{3}$

Despite his findings, this paper argues that there is a role of core industrial designers in ecodesign and that this role is at the operational end of ecodesign. The author suggests that the lack of involvement in operational issue (such as materials specification) identified in Sherwin's study arose as a result of his dealings with concept industrial designers rather than core industrial designers. This would account for their lack of interest in detail and their strong draw to concepts and scenarios ${ }^{3}$.

Within his study, Sherwin ${ }^{3}$ also recognises that conceptual design constitutes Industrial Design's most important input in to ecodesign, as it is at the stage where they have the highest levels of engagement with ecodesign. With this finding the author agrees. It is clearly true that re-thinking lifestyles (level 4 ecodesign, in Brezet's model of ecoinnovation ${ }^{24}$, Figure 3) will lead to greater increases in sustainability compared with redesigning products (level 1 in Figure 3). However, considering that industrial designers 
typically spend $90 \%$ of their time focusing on this 'operational' end of design (on core and continuous improvement projects) ${ }^{25}$, it is felt that recognising that industrial designers have a valuable role to play at this end of ecodesign, is vital. In recognition of this, it is also important to support this approach to ecodesign because unless a better understanding of the way in which 'operational' ecodesign should be undertaken is developed, companies such as Electrolux, who are focusing on developing more sustainable product concepts will not have the means to transform these concepts into reality.

It should also be recognised at this point, that within ecodesign theory and practice a belief that industrial designers have the same role to play in ecodesign as design engineers, seems to be developing. Although there is no known evidence of this being explicitly argued, the belief does appear to be intimated in ecodesign literature where industrial designers and design engineers are 'lumped' together under the umbrella of product development. This has also been mirrored by empirical evidence which illustrates that industrial designers are regularly given the same environmental information and tools as design engineers, to support ecodesign practice ${ }^{4}$.

\section{The role of core industrial designers at the operational end of ecodesign}

This section will provide evidence to demonstrate that core industrial designers have a role to play at the operational end of ecodesign, where the aim is to "translate product ideas into concrete ideas" ${ }^{2}$, and that this role differs from that of design engineers.

\subsection{Analysing the data requirements of industrial designers involved in ecodesign}

The data collected from the empirical study regarding the types of information that the industrial designers identified as being important to support the integration of ecodesign practice into product development ${ }^{4}$ provides interesting evidence to support the theory that core industrial designers work at the operational end of ecodesign. 
Within the study it was seen that the participants were looking for a combination of focused, relevant information and inspirational ideas, as they do in regular design ${ }^{4}$. Understanding what was considered to be 'relevant' information again helps to confirm that core industrial designers are focusing at the operational end of ecodesign. The feedback from the designers identified that they were looking for information on all of the following;

- $\quad$ styling trends;

- different applications for materials;

- details on new types of fixings;

- information and diagrams showing how products worked;

- details of materials/ fixings/ technology suppliers;

- $\quad$ assembly details;

- the technologies/mechanisms used (transferable technologies);

- $\quad$ how the products were manufactured; and

- links to where they could buy products, so that they could take them apart themselves.

The findings showed that the designers were looking for information to support the operational end of ecodesign, to help them to turn ideas into reality. They were looking for practical support that would help them to actually 'do' ecodesign. The findings showed that the information being asked for was very similar in nature to that which is regularly used to support regular design. Information which is widely recognised as being an important element of design projects ${ }^{19,26,27}$ in terms of stimulating new ideas for products and gaining critical commentary on emerging ideas ${ }^{28}$. 
As in regular design, their information requirements were broad and far reaching. They also varied dramatically from the types of ecodesign content previously provided for design teams, which has often consisted of technically focused statements presented in large documents, for example,

"Design for PS or PS-HI, avoid SAN and ABS.

Avoid PVC in the product as well as in the packaging (6.2). Use PE or PP where possible... Marking polymers with symbols to show their type, simplifies and promotes the recycling procedure of discarded home appliances.

All plastic and rubber (except extruded elastomers) parts (>50g or A>200 mm2) should be marked according to this standard." 29

These findings show that industrial designers' requirements for ecodesign, are very similar to those that they have in regular design but with an ecodesign bias. These findings suggest that core industrial designers are ideally looking to focus on similar issues to those which they consider in regular product design and that they have a similar role to play in ecodesign as they do in regular design.

\subsection{Analysing the contribution that industrial designers make in ecodesign projects}

By referring to the literature and selecting ecodesign case studies in which industrial designers have been involved it is possible to develop an understanding of the role that they have played in the development of these products. Through carrying out this type of analysis it is possible to develop a rich understanding of the role that core industrial designers have played in ecodesign case studies presented in the literature.

The Kambrook Axis kettle shown in Figure $4{ }^{30}$, developed during the EcoReDesign programme at RMIT $^{31}$, provides a good example of an ecodesign product which utilised 
the design skills of industrial designers. It demonstrates that involving industrial designers in the product development team can add a new dimension to the design of ecodesign products, through the introduction of their wide range of skills and wide knowledge base. By looking beyond technological solutions and considering the psychology of the user through behavioural studies, the design team managed to identify a range of strategies that led to dramatic improvements to the environmental performance of the product. This example shows how the resultant product had an improved level of energy efficiency due to the fact that the Industrial Design team considered the psychology of the user, basic ergonomics and careful materials selection, rather than focusing on re-developing the component configuration of the element. In other words, they used the wide range of skills and areas of knowledge that they use in regular design, to solve the design brief. This indicates that industrial designers involved in ecodesign carry out a similar role to their role in regular design. One imagines that if a similar project were undertaken without the input of industrial designers, the result might have looked very different and taken a much more technical approach.

Similarly, when considering the Ikea a.i.r. chair, (presented in Figure $5^{32}$ ) one sees the same broad range of design skills being applied as they would be in any design project. During this design the design team would have considered; materials selection, construction techniques, the user and intended market, ergonomics and anthropometrics among other things. Again, the designers would have drawn from their design skills, to solve the ecodesign problem. The same follows for many other ecodesign focused projects ${ }^{33-36}$. 


\section{Conclusion}

This paper has argued that contrary to previous literature ${ }^{3}$, core industrial designers do have a valuable role to play in ecodesign. It has been shown that this role lies at the operational end of ecodesign, where they "translate product ideas into concrete ideas" ${ }^{2}$. It has also been seen that although this 'operational' role does not hold as much potential for radical change, as a more strategic approach might ${ }^{3}$, it is still a vital area to support, because of the high percentage of time spent focusing on these types of issues. In addition to this it is recognised that providing industrial designers with the ability to be able to implement ecodesign at the operational stage will vastly improve the likelihood of ecodesign products making it onto the market.

It has also been seen that industrial designers contribute to the operational role of ecodesign in much they way that they do in regular product development drawing on a very similar range of data (product focused information and inspirational ideas). This differentiates their approach from the more techno-focused approach favoured by design engineers. These findings confirm that as in regular design, industrial designers do have a different role to play in ecodesign to that carried out by design engineers (which is more technical and more focused on details). This is something which has not been recognised in ecodesign literature before.

The findings from the study have led to the conclusion that industrial designers have a very similar role to play in ecodesign as they do in regular design, which means that (with or without the environmental focus) core industrial designers are concerned with:

- generating ideas and developing design concepts;

- $\quad$ adding to the scope of projects; 
- developing concepts that are fit for purpose, pleasurable and easy to use; and,

- using manufacturing \& material knowledge, to design product concepts that are efficient and profitable to produce.

The fact that core industrial designers should have a similar role to play in ecodesign as they do in regular design is also supported by the fact that Sherwin's findings ${ }^{3}$ demonstrate that the role of concept designers in ecodesign, is again very similar to the role of concept designers in regular product development. It is however an unsurprising finding when one refers back to the definition of ecodesign given earlier, which stated that ecodesign can be considered to be the activity of product design (which considers economic, functional, aesthetic and safety issues) with the additional consideration of environmental issues. However, despite the simplicity of this finding, recognition of the similarity between the activities carried out in regular and ecodesign is not something that has previously been articulated in the ecodesign theory (instead it has been intimated that industrial designers have the same role to play as design engineers).

Recognition of the fact that core industrial designers have a similar role to play in both 'regular' and 'eco' design has great implications for the design of tools and resources for ecodesign. It requires recognition of the fact that industrial designers are still engaged in Industrial Design when they are carrying out ecodesign and that tools need to support this accordingly. It also requires recognition of the fact that industrial designers and design engineers are different, have different needs, a different focus and consequently, different requirements. Many current ecodesign tools which have been given to industrial designers were initially designed for design engineers and as such can have an inappropriate focus and content for industrial designers. Research has shown that this has led to confusion 
amongst industrial designers as to how they can contribute to ecodesign ${ }^{37}$. By having an understanding of the requirements of industrial designers and the expected outcome of their involvement in ecodesign it will be easier for Environmental Affairs departments to provide them with appropriate information. This knowledge should help to alleviate a common problem in ecodesign which sees environmental science disciplines imposing their understanding of the role of design onto designers, rather than accurately understanding the integrities of the design functions. Environmental Affairs departments need to be aware of the broad range of skills that industrial designers have and the wide range of ways in which they can contribute to ecodesign projects. New tools designed for industrial designers will need to be designed in keeping with the culture of Industrial Design and focus on the types of issues that they are interested in, in order to ensure that the full potential that industrial designers have to offer ecodesign projects, can be capitalised on. 
References

EN.REFLIST 


\section{Captions to Illustrations}

Figure 1 An adaptation of Roy's diagram ${ }^{12}$ to illustrate the four stages of the product design and development process and the functions responsible for each stage

Figure 2 Adaptation of the 'Cone of Industrial Design' 17

Figure 3 Four-stage model of ecodesign innovation ${ }^{24}$

Figure 4 The Axis Kettle ${ }^{30}$

Figure 5 Ikea a.i.r. (air filled chair) ${ }^{32}$

\section{Illustrations}

Figure 1:

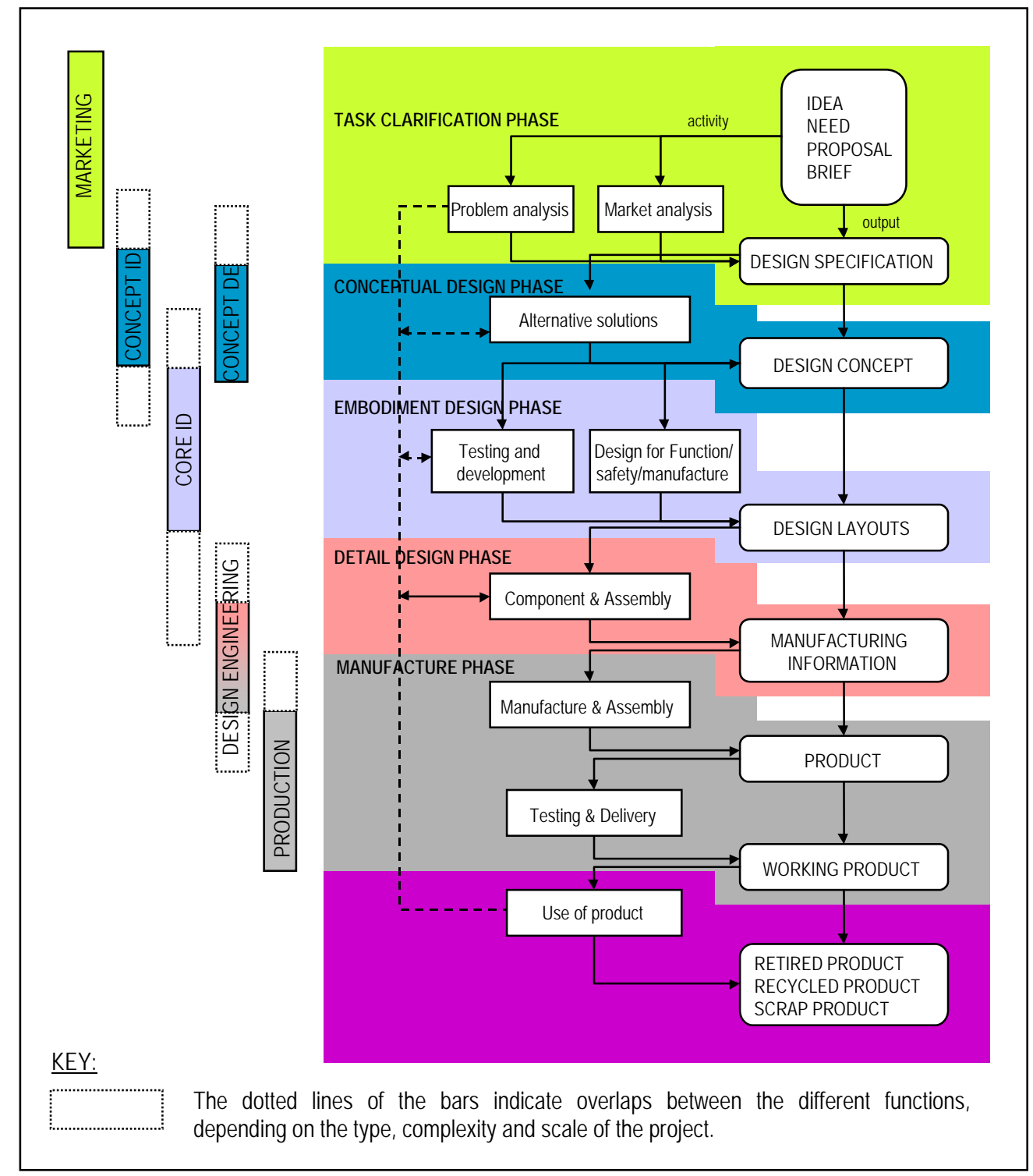


Figure 2:
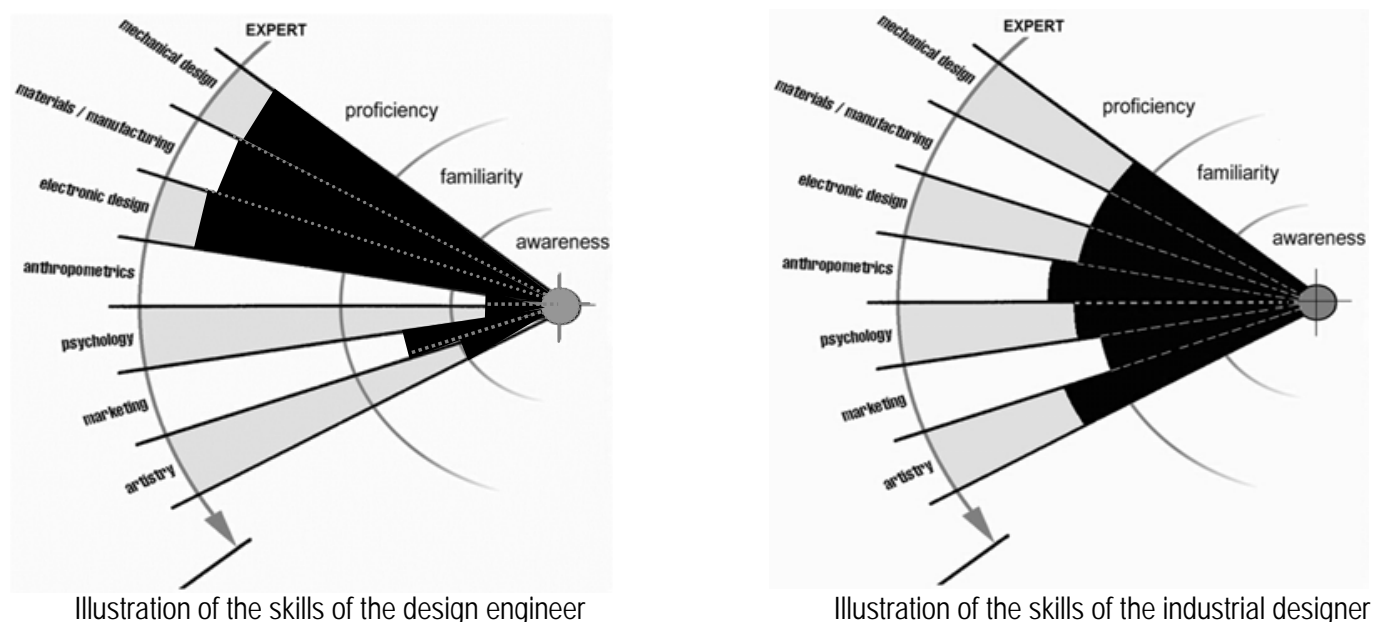

Illustration of the skills of the industrial designer

Figure 3:

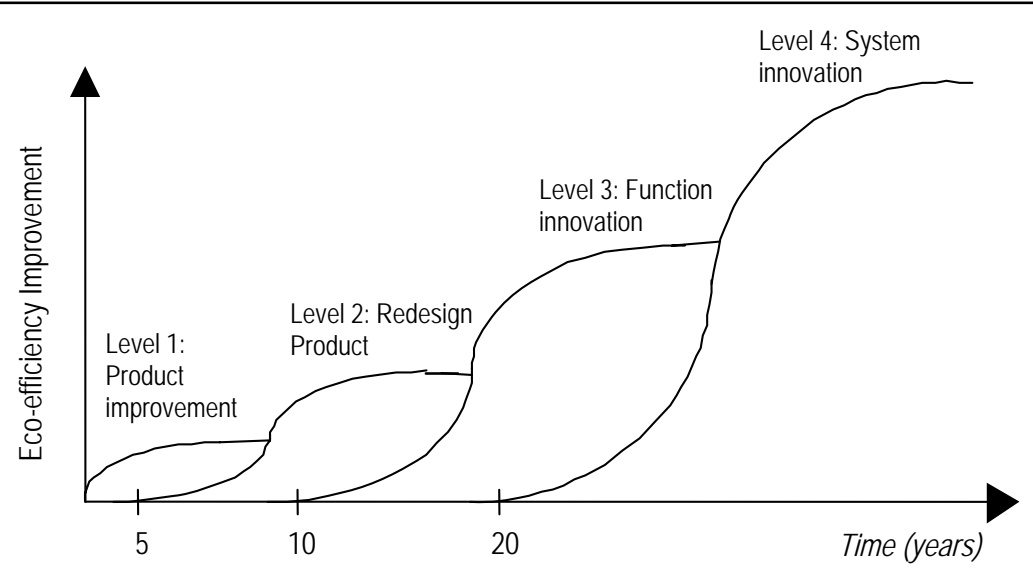

Product improvement: The improvement of existing products with regards to pollution prevention and environmental care. Products are made compliant.

Product redesign: The product concept stays the same, but parts of the product are developed further or replaced by others. Typical aims are increased reuse of spare parts and raw materials, or minimising the energy use at several stages in the product life cycle.

Function innovation: Involves changing the way the function is fulfilled. Examples include a move from paper-based information exchange to e-mail, or private cars to 'call-a-car' systems.

System innovation: New products and services arise requiring changes in the related infrastructure and organisations. A changeover in agriculture to industry-based food production, or changes in organisation, transportation and labour based on information technology. 
Figure 4:

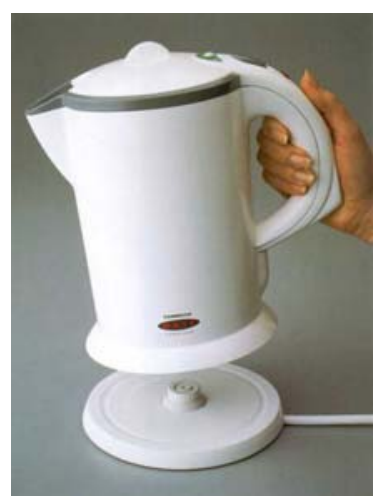

The aim of the project was to reduce the energy consumption of the kettle during use. Having found no suitable technological answer to the problem the design team studied the users' behaviour to see whether this provided any answers to the efficiency problems. The study concluded that users tend to fill the kettle fuller than required, turn the kettle on, walk off to do something, then come back 5 minutes later and reboil the kettle before using the hot water. These findings enabled the designers to identify three new ways of reducing the energy consumption of the kettle. The water gauge was made clearer and moved to the top of the jug. The jug cavity was insulated with a double wall, to keep the water hotter for longer and reduce the energy needed to reboil the kettle. A temperature indicator was fitted so the user could tell whether it was necessary to reboil the kettle.

Figure 5:

The Ikea a.i.r. chair is inflatable chair (which can be upholstered) is durable, reduces the number and quantity of materials used in comparison with the standard chair which in turn reduces the manufacturing costs and the costs (monetary and environmental) associated with transportation. In addition to this, it is not poisonous 